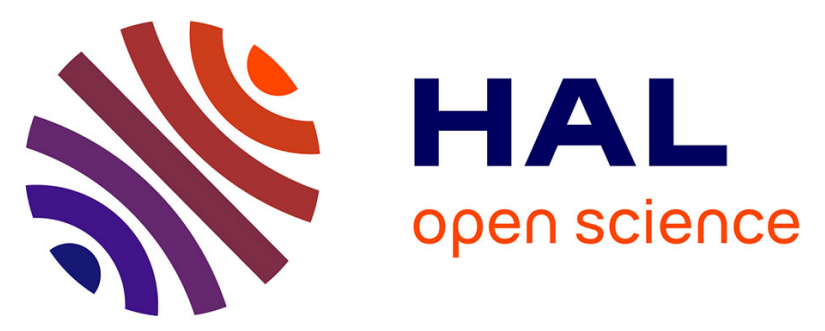

\title{
The Impact of Climate Change on the Potential Suitable Distribution of Major Crops in Zambia and the Countermeasures
}

\author{
Yanqin Wang, Zhen Tan, Guojun Sun
}

\section{- To cite this version:}

Yanqin Wang, Zhen Tan, Guojun Sun. The Impact of Climate Change on the Potential Suitable Distribution of Major Crops in Zambia and the Countermeasures. 8th International Conference on Computer and Computing Technologies in Agriculture (CCTA), Sep 2014, Beijing, China. pp.460-472, 10.1007/978-3-319-19620-6_52 . hal-01420261

\section{HAL Id: hal-01420261 \\ https://hal.inria.fr/hal-01420261}

Submitted on 20 Dec 2016

HAL is a multi-disciplinary open access archive for the deposit and dissemination of scientific research documents, whether they are published or not. The documents may come from teaching and research institutions in France or abroad, or from public or private research centers.
L'archive ouverte pluridisciplinaire HAL, est destinée au dépôt et à la diffusion de documents scientifiques de niveau recherche, publiés ou non, émanant des établissements d'enseignement et de recherche français ou étrangers, des laboratoires publics ou privés. 


\title{
The impact of climate change on the potential suitable distribution of major crops in Zambia and the Countermeasures
}

\author{
Yanqin Wang ${ }^{\mathrm{a}}$, Zhen Tan ${ }^{\mathrm{b}}$, Guojun Sun ${ }^{\mathrm{c}}$ \\ Institute of Arid Agroecology, School of Life Sciences, Lanzhou University, 730000 China \\ a'wangyq2012@1zu.edu.cn, ${ }^{b}$ tanzh13@1zu.edu.cn, ${ }^{c}$ sungj@1zu.edu.cn
}

\begin{abstract}
Climate change, as an inevitable process, will aggravate food shortage of the already vulnerable agriculture systems in Zambia. Rain-fed agriculture supports the livelihood of majority of smallholders in Zambia. To effectively adapt to foreseeable climate change, and to decrease risk of the food crisis, we analyzed potential suitable distribution of major crops (white maize (Zea mays), cassava (Manihot esculenta) and sorghum (Sorghum bicolor)) in Zambia under current and future (2080s) climates using the MCE-GIS (multicriteria evaluation -geographical information system) Planting Ecological Adaptability model. The simulation results indicate that climate change will change the potential suitable area for maize from $66.8 \%$ to $48.6 \%$; and that of cassava from $65 \%$ to $84 \%$. The suitable regions of sorghum move northward although the total areas will not change. We conclude that future climate change will have different effects on various crops. Our modeling results can be used to make appropriate management decisions and to provide farmers with alternative options for their farming system in responding to climate change.
\end{abstract}

Keywords: climate change, agriculture crisis, Zambia, MCE-GIS Planting Ecological Adaptability model, potential suitability, adaptation countermeasures

\section{Introduction}

About $80 \%$ of the variability of agriculture production is due to the variability in weather conditions, especially for rain-fed agriculture[1]. The lack of adaptive strategies to cope with this variability makes sub-Saharan Africa countries highly vulnerable to extreme weather events and climate change [2-5]. There is a growing number of evidence showing that in tropic and subtropical Africa, where crops have reached their maximum tolerance $[1,6]$, crops suitability and yields are likely to decrease due to the increased temperature [7, 8]. Thus, the declined crops yield 
eventually will cause substantial impact on food security of poor rain-fed rural communities in sub-Saharan Africa countries $[1,7]$.

Zambia is a landlocked country in central southern Africa. It has advantages of agricultural production, such as vast untapped agricultural lands, favorable climate conditions and adequate water resources $[9,10]$. Despite all of these advantages, Zambia has a very low food supply, and it is one of the 15 countries with the lowest food security worldwide [10]. Its farming system is depend on rainfall, and is characterized by low fertilizer inputs, low productivity and undeveloped markets [11]. Most of Zambia's farmers (75\%) are smallholders who consume most of their own productions[10]. White maize is the leading crop in Zambia, accounting for about $70 \%$ of cereals planting area [12-14]. Cassava is the sixth world food crop for more than 500 million people in tropical and sub-tropical Africa, Asia and America [15]. Sorghum is an indigenous cereal from Africa that is well adapted to African semi-arid and sub-tropical agronomic conditions, and also a kind of main source of protein crop in Zambia. Thus it is important to determine the potential distribution of white maize and other crops cultivation zones under future climatic scenarios. Even though there have been many studies concerned the impacts of climate change on the agricultural system of Zambia $[2,10,13]$, those studies have not focused on the response of individual crops to climate change.

In this study, we will use the MCE-GIS (multi-criteria evaluation -geographical information system) model to simulate suitable planting areas of three crops in Zambia. This model is particularly well suited to evaluate the potential suitability of the studied species in a given area according to its weather and geographical conditions, and to determine the crop potential suitable planting areas [16-18].

Our objectives are to: (1) rate the climatic suitability of white maize, cassava and sorghum cultivation distribution under current climate conditions in Zambia; (2) predict and simulate the white maize, cassava and sorghum suitable planting areas under future (2080s) climate conditions in Zambia; (3) analyze the variability of these three crops suitability and planting structure changes caused by climate change. It is expected that studies like this can provide a rational for better crop planning, 
improved land use and sustainable crop yields [3, 19], in the context of national scale adaptation to climate change $[2,13]$.

\section{$2 \quad$ Material and Methods}

\subsection{Study Area}

This study is conducted in Zambia, located in central southern Africa $\left(15^{\circ} \mathrm{S}, 30^{\circ} \mathrm{E}\right)$ (Fig.1). Although the country has a tropical climate, temperatures remain relatively cool throughout the year due the high altitudes of the East Africa Plateau. There are two main seasons. The rainy season (November to April) corresponding to summer has rainfall $150 \mathrm{~mm}$ to $300 \mathrm{~mm}$ per month, and the daily highest seasonal temperature in this season are $22^{\circ} \mathrm{C}$ to $27^{\circ} \mathrm{C}[20,21]$. Another is dry season (May to October), corresponding to winter (mean daily temperature is $15^{\circ} \mathrm{C}$ to $20^{\circ} \mathrm{C}$ ). The dry season is subdivided into cool dry season (May to August) and hot dry season (September to October). These months are very dry, receiving almost no rainfall between [21].

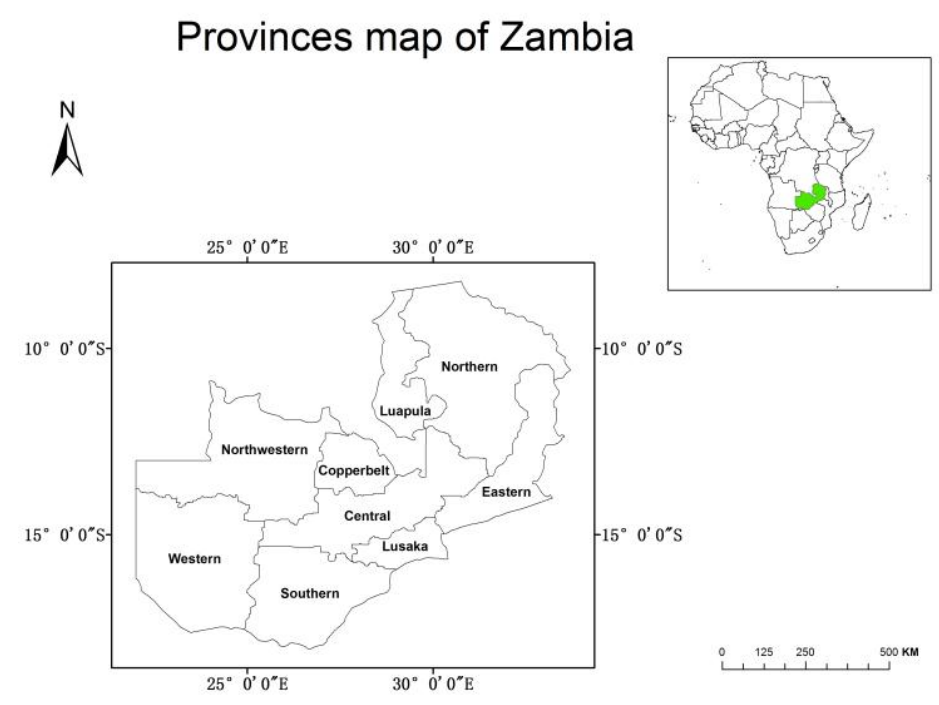

Fig. 1. Provincial boundary map of Zambia

The main crops in Zambia are white maize (Zea mays), sorghum (Sorghum bicolor), 
millet (Pennisetum glaucum), cassava (Manihot esculenta), wheat (Triticum aestivum), groundnut (Arachis hypogaea) and cotton (Gossypium herbaceum) [10]. The main crop growing season lasts from November to April, and almost entirely dependent on rains. There is a minor cropping season from June to September, in this dry season commercial farmers use irrigation to plant wheat. However no analysis is conducted for this minor season in this study.

\subsection{Climate indices and meteorological data}

The climate indices affecting the distribution of cultivation zones of the three crops are listed below (all the meteorological data is for growth period from November to April): accumulative daily mean temperature above $10^{\circ} \mathrm{C}$ (AT); monthly average maximum temperature (Max-T); monthly average minimum temperature (Min-T); and monthly precipitation (PRE) [15, 22-25].

Meteorological data (50 year normal of 1950-2000) is downloaded from the Website of WorldClim-Global Climate Data (http://www.worldclim.org) with 1 00square kilometer resolution [26]. It was interpolations of observed data.

Future conditions of the meteorological data (2080s) is the downscaled global climate model (GCM) data from Fourth Coupled Model Intercomparison Project (CMIP4) $[19,27]$. We choose Coupled Global Climate Model (CGCM3) outputs under SRA1B emissions scenarios. The model was developed by Canadian Centre for Climate Modeling and Analysis (CCCma) [27]. This model produces a good simulation for future conditions meteorological especially for Sub-Saharan Africa [28]. These data sets are often used for environmental, agriculture and biological sciences [26]. The A1 scenario family describes a future world of very rapid economic growth, global population that peaks in mid-century and declines afterwards, and rapid introduction of new and more efficient technologies [19, 29]. The A1 scenario family divided into three groups(A1FI, A1B, A1T ) describes an alternative directions of technological change in the energy system [19]. The three A1 groups are distinguished by their technological emphasis. The A1B is defined as not relying too 
heavily on one particular energy source and on the assumption that similar improvement rates apply to all energy supply and end-use technologies [19, 29]. The resolution of the data is 30 seconds.

\subsection{Soil and elevation data}

The soil data is from Harmonized World Soil Database, including soil $\mathrm{pH}(\mathrm{PH})$ data and soil texture data (Soil-T). (http://webarchive.iiasa.ac.at/Research/LUC/ExternalWorld-soil-database/HTML/).

We obtained the field moisture capacity data using equation 1 [30].

$\mathrm{FMC}=0.003075 \times$ Sand $+0.005886 \times$ Silt $+0.008039 \times$ Clay $+0.002208 \times$ OM $0.14340 \times$ Bulk_Density.

Where:

FMC- field moisture capacity; Sand- soil sand content (\%), the US system; Silt-soil silt content (\%), the US system; Clay-soil clay content (\%), the US system; OM-soil organic matter (SOM) content (\%); Bulk_Density-soil bulk density $\left(\mathrm{g} / \mathrm{cm}^{3}\right)$.

The elevation data is downloaded from the website of ASTER Global Digital $\begin{array}{llll}\text { Elevation } & \text { Model } & \text { (ASTER }\end{array}$ (http://www.jspacesystems.or.jp/ersdac/GDEM/E/4.html). The resolution of the data is $30 \mathrm{~m}$.The land-use data in this study is downloaded from Web-site Center for Earth System Science of Tsinghua University, (http://www.cess.tsinghua.edu.cn/publish/essen/index.html).

\subsection{MCE-GIS Planting Ecological Adaptability model}

The MCE-GIS Planting Ecological Adaptability model has been effectively used to predict the crop distribution and evaluate land suitability [17, 18, 32, 33]. It is based on geographical information system (GIS) and the multi-criteria evaluation (MCE) $[16,34]$. MCE can be defined as a set of systematic procedures that used to analyzing complex decision problems. This model transforms geographical data into resultant decision by using the regular criteria and an evaluation matrix. It also provides 
function to visualize the model outputs using GIS tool $[35,36]$. All operations carried out in GIS and MATLAB software. A diagram of the methods used is shown in Fig.2. We run the MCE-GIS Planting Ecological Adaptability model for Zambia[37]. Some important procedures are further described below.

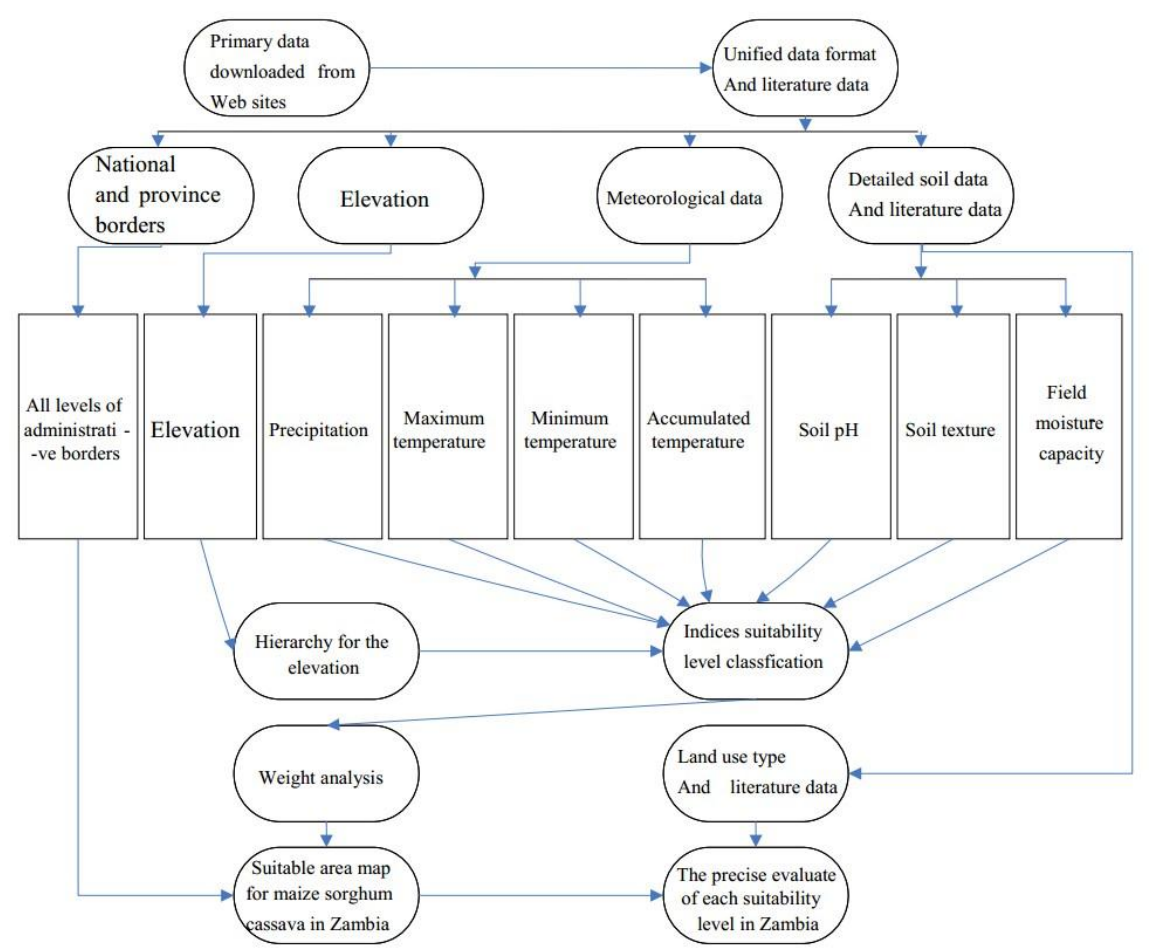

Fig. 2. The MCE-GIS Planting Ecological Adaptability model procedures

Firstly, we use eight indices data, (i.e. the accumulative of daily mean temperature above $10^{\circ} \mathrm{C}(\mathrm{AT})$, monthly mean maximum temperature (Max-T), monthly mean minimum temperature (Min-T), monthly precipitation (PRE), elevation, soil texture (Soil-T), soil $\mathrm{pH}(\mathrm{PH})$ and field moisture capacity (FMC))to generate various thematic layers using GIS software. These indices were classified into five levels according to suitability (table.1; table.2; table.3). In this study, we adopted the FAO classification system for crops, which allows for land suitability rating based on soil and environmental characters. The FAO system has five classes of suitability rating 
for certain crops. The five classes are very high, high, medium, low and very low[38]. The specific suitability level of each index was defined based on experts' advice and literature reviews $[15,22-25,39]$.

Secondly, we calculated weight of each of the indices using pair-wise comparison matrix known as analytical hierarchy process (AHP). The ratings were provided on a nine-point scale. The comparison concerns the relative importance of each two indices involved in determining the suitability of the stated objective, and the value ranges from 9 to $1 / 9$. The weight coefficient is calculated with MATAB software (talbe.4). [15, 22-25, 39].

Finally, we simulated and derived the final potential suitability level maps of each crop using the indices and weight factors.

Table 1. Each index suitability level classification of white maize in Zambia

\begin{tabular}{|c|c|c|c|c|c|}
\hline \multirow[b]{2}{*}{ Index } & \multicolumn{5}{|c|}{ Level of suitability } \\
\hline & Very high & High & Medium & Low & Very low \\
\hline $\begin{array}{l}\text { Accumulative } \\
\text { temperature } \geq 10^{\circ} \mathrm{C}\end{array}$ & $3800-4300$ & $4300-4800$ & $3600-3800$ & $4800-5000$ & $\begin{array}{l}<3600 \\
\text { or }>5000\end{array}$ \\
\hline Precipitation $(\mathrm{mm})$ & $850-1050$ & $\begin{array}{l}1050-1200 \\
\text { or } 750-850\end{array}$ & $\begin{array}{l}1200-1300 \\
\text { or } 650-750\end{array}$ & $1300-1500$ & $\begin{array}{l}<650 \\
\text { or }>1500\end{array}$ \\
\hline $\operatorname{Max} \operatorname{Temp}\left({ }^{\circ} \mathrm{C}\right)$ & $28-31$ & $\begin{array}{l}31-32 \text { or } \\
26-28\end{array}$ & $32-33$ & $\begin{array}{l}33-34 \text { or } \\
24-26\end{array}$ & $\begin{array}{l}<24 \text { or } \\
>34\end{array}$ \\
\hline $\operatorname{Min} \operatorname{Temp}\left({ }^{\circ} \mathrm{C}\right)$ & $16-19$ & $\begin{array}{l}19-20 \text { or } \\
15-16\end{array}$ & $14-15$ & $20-21$ & $\begin{array}{l}<14 \text { or } \\
>21\end{array}$ \\
\hline $\begin{array}{l}\text { Field moisture } \\
\text { capacity }(\%)\end{array}$ & $0.30-0.35$ & $\begin{array}{cc} & 0.25-0.30 \\
\text { or } \quad 0.35-0.4\end{array}$ & 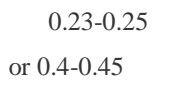 & $0.18-0.23$ & $\begin{array}{l}<0.18 \text { or } \\
>0.45\end{array}$ \\
\hline Soil pH & $6.3-7.0$ & $\begin{array}{l}5.5-6.3 \text { or } \\
7.0-7.5\end{array}$ & $7.5-8.0$ & $5.0-5.5$ & $\begin{array}{l}<5 \text { or } \\
>8\end{array}$ \\
\hline Elevation (m) & $<1200$ & $1200-1300$ & $1300-1500$ & $1500-1800$ & $>1800$ \\
\hline Soil texture & Loam & Sand & Clay & - & Other \\
\hline
\end{tabular}

Table 2. Each index suitability level classification of cassava in Zambia

Index Level of suitability




\begin{tabular}{|c|c|c|c|c|c|}
\hline & Very high & High & Medium & Low & Very low \\
\hline $\begin{array}{l}\text { Accumulative } \\
\text { temperature } \geq 10^{\circ} \mathrm{C}\end{array}$ & $4200-5000$ & $3900-4200$ & $5000-5300$ & $3700-3900$ & $\begin{array}{l}<3700 \text { or } \\
>5300\end{array}$ \\
\hline Precipitation (mm) & $600-1000$ & $\begin{array}{l}500-600 \text { or } \\
1000-1200\end{array}$ & $1200-1400$ & $1400-1500$ & $\begin{array}{l}<500 \text { or } \\
>1500\end{array}$ \\
\hline $\operatorname{Min}$ Temp $\left({ }^{\circ} \mathrm{C}\right)$ & $27-31$ & $\begin{array}{l}25-27 \text { or } \\
31-33\end{array}$ & $33-34$ & $\begin{array}{l}24-25 \\
34-35\end{array}$ & $\begin{array}{l}<24 \text { or } \\
>35\end{array}$ \\
\hline $\operatorname{Max}$ Temp $\left({ }^{\circ} \mathrm{C}\right)$ & $17-21$ & $\begin{array}{l}16-17 \text { or } \\
21-22\end{array}$ & $22-23$ & $15-16$ & $\begin{array}{l}<15 \text { or } \\
>23\end{array}$ \\
\hline $\begin{array}{ll}\text { Field } & \text { moisture } \\
\text { capacity } & (\%)\end{array}$ & $0.3-0.38$ & $\begin{array}{l}0.25-0.3 \text { or } \\
0.38-0.42\end{array}$ & $0.42-0.45$ & $0.18-0.25$ & $\begin{array}{l}<0.18 \text { or } \\
>0.45\end{array}$ \\
\hline Soil pH & $6-7$ & $5-6$ & $4.5-5$ & $\begin{array}{l}3.8-4.5 \text { or } \\
7-7.8\end{array}$ & $\begin{array}{l}<3.8 \text { or } \\
>7.8\end{array}$ \\
\hline $\begin{array}{l}\text { Elevation } \\
\text { Soil texture }\end{array}$ & $\begin{array}{l}<1000 \\
\text { loam }\end{array}$ & $\begin{array}{l}1000-1300 \\
\text { sand }\end{array}$ & $1300-1400$ & $\begin{array}{l}1400-1600 \\
\text { clay }\end{array}$ & $\begin{array}{l}>1600 \\
\text { other }\end{array}$ \\
\hline
\end{tabular}

Table 3. Each index suitability level classification of sorghum in Zambia

\begin{tabular}{|c|c|c|c|c|c|}
\hline \multirow{2}{*}{ Index } & \multicolumn{5}{|c|}{ Level of suitability } \\
\hline & Very high & High & Medium & Low & Very low \\
\hline Accumulative & $4200-4900$ & $3900-4200$ & $4900-5200$ & $3600-3900$ & $<3600$ or \\
\hline temperature $\geq 10^{\circ} \mathrm{C}$ & & & & & $>5200$ \\
\hline \multirow[t]{2}{*}{ Precipitation (mm) } & $700-900$ & $500-700$ or & $1050-1200$ & $1200-1400$ & $<500$ or \\
\hline & & $900-1050$ & & & $>1400$ \\
\hline \multirow[t]{2}{*}{$\operatorname{Max} \operatorname{Temp}\left({ }^{\circ} \mathrm{C}\right)$} & $28-31$ & $25-28$ & $31-33$ & $33-35$ & $<24$ or \\
\hline & & & & $24-25$ & $>35$ \\
\hline \multirow[t]{2}{*}{$\operatorname{Min} \operatorname{Temp}\left({ }^{\circ} \mathrm{C}\right)$} & $17-20$ & $15-17$ or & $14-15$ & $21-23$ & $<14$ or \\
\hline & & $20-21$ & & & $>23$ \\
\hline Field moisture & $0.3-0.36$ & $0.25-0.3$ or & $0.4-0.45$ & $0.18-0.25$ & $<0.18$ or \\
\hline capacity & & $0.36-0.4$ & & & $>0.45$ \\
\hline \multirow[t]{2}{*}{ Soil pH } & $6.5-7.5$ & $6-6.5$ & $5.0-6.0$ or & $>8.0$ & $<5.0$ \\
\hline & & & $7.5-8.0$ & & \\
\hline Elevation(m) & $<1000$ & $1000-1200$ & $1200-1300$ & $1300-1600$ & $>1600$ \\
\hline Soil texture & Loam & Sand & Clay & $\underline{-}$ & Other \\
\hline
\end{tabular}


Table 4. Each index weight coefficient of crops using AHP

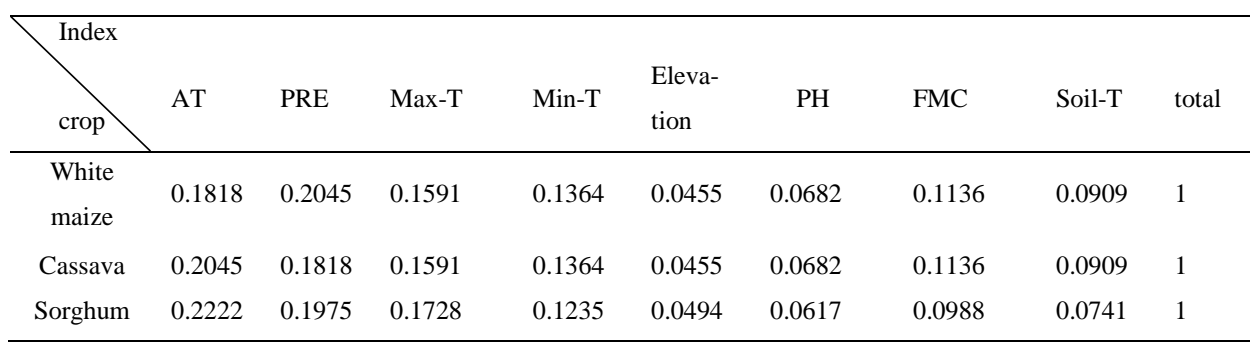

AHP- analytical hierarchy process; AT- Accumulative temperature $\geq 10^{\circ} \mathrm{C}$; PRE- Precipitation;

Max-T- monthly mean maximum temperature; Min-T- monthly mean minimum temperature;

PH- soil pH; FMC- field moisture capacity; Soil-T- soil texture

\section{Results and Discussion}

\subsection{Simulation of white maize, sorghum and cassava suitability under current} climate conditions

Under current climate conditions, maize is widely suitable in Zambia; the potential suitable provinces for white maize include Western, Eastern, Central, Southern and Lusaka provinces and part of Northwest province. The suitable area occupies more than $66.8 \%$ of the total country area and counts for $5.03 \times 10^{7}$ ha (Fig.3, maize). Cassava potential suitability area $\left(65 \%\right.$ of the total country area or $4.90 \times 10^{7}$ ha) is lower than maize, and covers Western, Eastern, Central, Southern and Lusaka provinces and part of Northwest province (Fig.3, cassava). Sorghum is the thirdly most suitable crop in Zambia $\left(55.2 \%\right.$ of total country area or $4.90 \times 10^{7}$ ha; Fig.3, sorghum). Most of potential suitable areas of sorghum are located in Western, Lusaka, Southern and Center provinces. 
Current potential suitable level map for maize, cassava and sorghum in Zambia
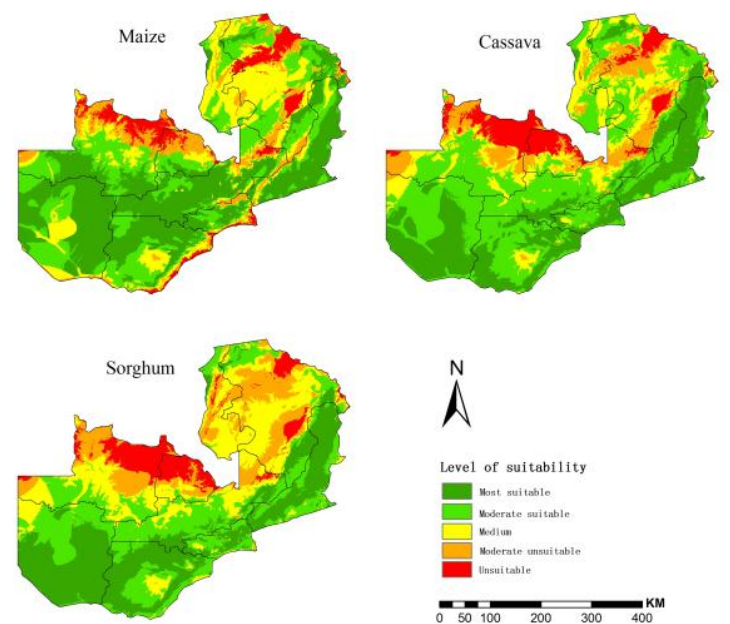

$\bigwedge^{N}$

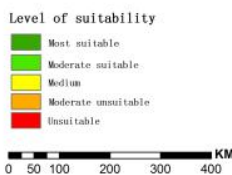

Fig. 3. White maize, cassava and sorghum potential suitable distribution area under current climate in Zambia

\subsection{Simulation of white maize, sorghum and cassava suitability under future climate conditions}

Under future climate conditions, the accumulated temperature will increase, the precipitation will increase particularly in the northeast of Zambia, monthly average maximum temperature and monthly average minimum temperature will increase about $3{ }^{\circ} \mathrm{C}$. In the southern and western regions of Zambia warmer rate is slightly more rapid than that in northern and eastern regions of Zambia.

With climate change, the maize suitable area decreases from $66.8 \%$ to $48.6 \%$ $\left(3.66 \times 10^{7} \mathrm{ha}\right)$ of the total country area (Fig.4), and the potential suitable region changes into most of the Central, Northwest and Northern provinces (Table.5). Cassava will benefit from increased temperature. It will become the most suitable one among these three crops in Zambia $\left(84 \%\right.$ of the total country area or $6.33 \times 10^{7}$ ha; Fig.4), covers almost the whole country except for part of the north border strip of Zambia (Table.5). There is little change on potential suitability percentage in whole country of sorghum $\left(55.5 \%\right.$ of the total country areas or $4.18 \times 10^{7}$ ha; Fig. 4$)$, however, potential suitable region moves northward. The southwest part of Western province 
becomes not suitable for sorghum, whereas, the Northern province from unsuitable becomes potential suitable area for sorghum planting (Table.5).

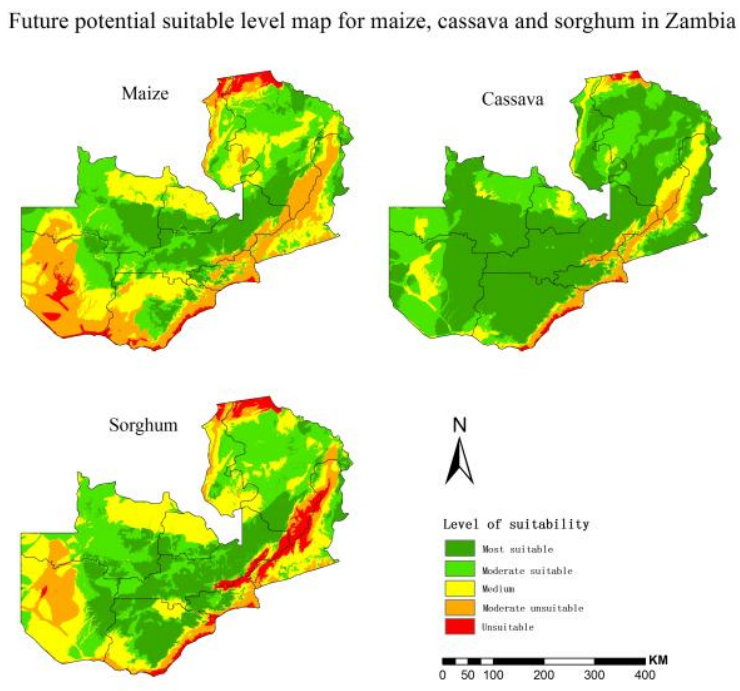

Fig. 4. White maize, cassava and sorghum potential suitable distribution area under future climate in Zambia

Table 5. Simulated planting area percentage for three crops in the current and the future climate conditions in each province of Zambia

\begin{tabular}{ccccccc}
\hline $\begin{array}{l}\text { Province } \\
\text { Name }\end{array}$ & $\begin{array}{c}\text { Potential planting area } \\
\text { percent } \\
\text { for maize (\%) }\end{array}$ & \multicolumn{2}{c}{$\begin{array}{c}\text { Potential planting } \\
\text { area percent } \\
\text { for sorghum(\%) }\end{array}$} & \multicolumn{2}{c}{$\begin{array}{c}\text { Potential planting } \\
\text { area percent } \\
\text { for cassava(\%) }\end{array}$} \\
\cline { 2 - 7 } & current & future & current & future & current & future \\
\hline Northwester & 56.31 & 69.14 & 21.12 & 64.57 & 35.07 & 95.76 \\
Luapula & 32.45 & 35.96 & 14.20 & 35.54 & 45.38 & 83.86 \\
Eastern & 87.16 & 23.91 & 96.04 & 24.80 & 96.98 & 59.40 \\
Northern & 40.95 & 59.28 & 24.23 & 65.85 & 43.29 & 83.80 \\
Western & 87.38 & 23.40 & 93.41 & 36.68 & 93.69 & 88.11 \\
Lusaka & 71.33 & 34.32 & 92.38 & 49.54 & 94.90 & 61.06 \\
Southern & 76.74 & 29.06 & 92.35 & 59.73 & 93.52 & 80.73 \\
Copperbelt & 39.91 & 51.79 & 25.71 & 47.66 & 13.04 & 81.16 \\
Central & 83.24 & 82.82 & 63.90 & 84.74 & 72.83 & 91.17 \\
\hline
\end{tabular}


The results obtained under current climate conditions are consistent with previous studies $[10,13]$. They indicate that climate warming will have negative impact on the suitability of white maize, but will have positive impacts on cassava. Sorghum suitable planting area will move to the high altitude areas of Zambia. This result is in agreement with the IPCC report, which stated if the temperature increases $1^{\circ} \mathrm{C}$, the crops suitable altitude will move up $100 \mathrm{~m}[5]$. Furthermore, there is a generally agreement that in the Mediterranean, tropical and sub-tropical climatic zones, all the crop suitability will decrease with the warming trend of climate change, which contrasts with the increased suitability with global warming at higher latitudes[25]. In order to adapt to climate change, planting structure should be adjusted.

For white maize, the potential suitability benefits can usually be expected in cooler or higher elevation locations. The maximum temperature threshold is $34^{\circ} \mathrm{C}$, as temperature sharply increasing to more than $4{ }^{\circ} \mathrm{C}$ in Western, Southern, Eastern and Lusaka provinces during the growing period of white maize, their temperature will be above the threshold, and this can cause the death of white maize[40]. Most areas of aforementioned provinces will see reduced white maize potential suitable areas. In contrast, Northern and Northwestern provinces at high altitudes, potential suitability areas of white maize will increase as temperature increases to its suitable limit.

Cassava can tolerant to both poor soil and harsh climate conditions[15]. Under current climate conditions, it is mainly grown in marginal, low-fertility acidic soils under variable rain-fed conditions (less than $600 \mathrm{~mm}$ precipitation per year). That is due to people's preference for maize, and its remarkable tolerance to nature stress and adverse environments in contrast with input-demanding and capital intensive cereal crops, such as maize and wheat [13]. This leads to no enough excellent farmland for cassava. Given cassava is a root crop, it can be continuously harvested. It can also maintain high photosynthetic potential in aridity environments with sporadic rainfall[15]. Besides, it prefers high temperature [41]. It is hence generally benefit from the increasing temperature caused by changing climate. From the result obtained by simulation model, we concluded that cassava's potential suitability areas expand into almost the whole country as temperature increases, except for the south edge of 
Zambia where temperature sharply increases and exceeds the threshold. The expansion scenario is also supported by the sufficient rainfall around the country under future scenarios.

For sorghum, the potential suitability area is decreased as a result of warming in the south and west part of Zambia. In contrast the potential suitability of areas of sorghum in Northern, Northwestern and Central provinces are increased. If temperature raises less than $2^{\circ} \mathrm{C}$, rainfall change can modulate the magnitude of the negative impact, but the warmer temperature exceeds $2^{\circ} \mathrm{C}$ in the whole Zambia, negative impacts caused by temperature rise cannot be mitigated by any rainfall increase [39]. Thus sorghum potential suitability areas northward migration is the result of temperature and precipitation increase caused by climate change.

The impact of climate change on crop planting and production may be a slow process, but the consequence is irreversible [7, 25]. In order to minimize the negative effects of climate, the stakeholders and society should formulate and implement adaptive measures.

There are two aspects of strategies we can take into consideration, one is national level strategies the other is farm level adaptations strategies. The former aspect including rural credit facility strategies, output products strategies, investment technological innovations and expansion of irrigation, and so on. Although relatively costly national strategies may effectively moderate negative impacts and result in biggest benefits, considering the limitations of subsistence farmers, it difficult to implement for smallholders, thus, suggest that small-scale and affordable solutions for subsistence farmers would be more benefit $[1,7,42]$. We focus on the second aspect, some inexpensive strategies that smallholders can implement based on this study. Firstly, switch crops from less potential suitable areas to higher potential suitable areas. Maize should be planted in most of the Northwest, Center and Northern provinces in the future. Sorghum should be planted move to northward, in Northwest, Center, Northern and Southern provinces. Cassava as a hot resistant crop, as temperature increase its suitable area scope will expand to the whole country. Secondly, cassava grows better than other staples including potato, maize, beans, sorghum, millet, banana from 24 climate different prediction models [43]. Cassava as 
the underutilized crop, following its high suitability in the future in Zambia, it is recommended to improve cassava availability. We have identified cassava as a key crop for the future from this study also from other former studies [43].

\section{Conclusions}

In this study, we simulated the distribution of white maize, cassava and sorghum under both current and future climate scenarios in Zambia. Our results indicate that, the suitability of these three crops will increase in high altitude regions in the northern Zambia; the growing temperature will have negative impacts on maize whereas cassava will benefit, and sorghum suitable areas will migration to the north of Zambia.

We outlined agricultural adaptation strategies in this study, that is, sorghum should be planted move to northward to the high altitude provinces; cassava as a hot resistant crop, its suitable area should be expanded to the whole country; reduce maize cultivation area.

\section{Acknowledgment}

The author is grateful for the funding from the Projects: 2012DFG31450 and 0S2014GO0481. Appreciate those constructive review and comments from Prof. Fernando T. Maestre, Mr. Xiaoyuan Geng, Dr. Jansheng Ye and Mr. Baocheng Jin.

\section{References}

1.Cooper PJM, Dimes J, Rao KPC, et al. Coping better with current climatic variability in the rain-fed farming systems of sub-Saharan Africa: an essential first step in adapting to future climate change? [J]. Agriculture, Ecosystems \& Environment, 2008, 126(1):24-35.

2.Thurlow J, Zhu T, Diao X. Current climate variability and future climate change: estimated growth and poverty impacts for Zambia [J]. Review of Development Economics, 2012, 16(3):394-411.

3.Howden SM, Soussana J-F, Tubiello FN, et al. Adapting agriculture to climate change [J]. Proceedings of the National Academy of Sciences, 2007, 104(50):19691-19696. 
4.You L, Wood S, Wood-Sichra U. Generating plausible crop distribution maps for SubSaharan Africa using a spatially disaggregated data fusion and optimization approach [J]. Agricultural Systems, 2009, 99(2):126-140.

5.Alexander LV, Allen SK, Bindoff NL, et al. Climate Change 2013:Summary for Policymakers [M]. Cambridge: Cambridge Univ. Press, 2013, 19-21

6.FAO. Water for agriculture and energy in Africa: The challenges of climate change [M]. Roma: The State of Food and Agriculture. FAO, 2008, 129-131

7.Thompson HE, Berrang-Ford L, Ford JD. Climate change and food security in sub-Saharan Africa: a systematic literature review [J]. Sustainability, 2010, 2(8):2719-2733.

8.Brown ME, Funk CC. Food security under climate change [J]. science, 2008, 319(5863):580581.

9.McSweeney C, Lizcano G, New M, et al. The UNDP Climate Change Country Profiles: Improving the accessibility of observed and projected climate information for studies of climate change in developing countries [J]. Bulletin of the American Meteorological Society, 2010, 91(2):157-166.

10.Neubert S, Kömm M, Krumsiek A, et al. Agricultural Development in a Changing Climate in Zambia [M]. Bonn, Germany: German Development Institute (DIE), 2011, 1-9

11.Seshamani V. The impact of market liberalisation on food security in Zambia [J]. Food Policy, 1998, 23(6):539-551.

12.Hamazakaza P, Smale M, Kasalu H. The Impact of Hybrid Maize on Smallholder Livelihoods in Zambia: Findings of a Household Survey in Katete, Mkushi, and Sinazongwe Districts [J]. Indaba Agricultural Policy Research Institute working paper 73, 2013, 1(1):126.

13.Jain S. An empirical economic assessment of impacts of climate change on agriculture in Zambia [J]. World Bank Policy Research Working Paper, 2007, 1(4291):2-24.

14.Byerlee D, Eicher CK. Africa's emerging maize revolution [M]. United State of America: Lynne Rienner Publishers, 1997, 3-23

15.El-Sharkawy MA. Cassava biology and physiology [J]. Plant molecular biology, 2004, 56(4):481-501.

16.Malczewski J. GIS and multicriteria decision analysis [M]. Canada: John Wiley \& Sons, 1999, 3-260

17.Jia Chaojie, Wang Lele, Luo Xiaoli, et al. Evaluation of Suitability Areas for Maize in China Based on GIS and Its Variation Trend on the Future Climate Condition. In: Cao B-Y, Ma S-Q, Cao H-h, editors. Ecosystem Assessment and Fuzzy Systems Management [M]: Springer International Publishing, 2014, 285-299.

18.He Wenying, Wang Lele, Luo Xiaoli, et al. The Trend of GIS-Based Suitable Planting Areas for Chinese Soybean Under the Future Climate Scenario. In: Cao B-Y, Ma S-Q, Cao $\mathrm{H}-\mathrm{h}$, editors. Ecosystem Assessment and Fuzzy Systems Management [M]: Springer International Publishing, 2014, 325-338.

19.Parry ML. Climate Change 2007: impacts, adaptation and vulnerability: contribution of Working Group II to the fourth assessment report of the Intergovernmental Panel on Climate Change [M]: Cambridge University Press, 2007, 80-248

20.Reason C, Hachigonta S, Phaladi R. Interannual variability in rainy season characteristics over the Limpopo region of southern Africa [J]. International journal of climatology, 2005, 25(14):1835-1853.

21.Usman MT, Archer E, Johnston P, et al. A conceptual framework for enhancing the utility of rainfall hazard forecasts for agriculture in marginal environments [J]. Natural Hazards, 2005, 34(1):111-129.

22.Hoogenboom G. Contribution of agrometeorology to the simulation of crop production and its applications [J]. Agricultural and forest meteorology, 2000, 103(1):137-157. 
23.Tadross M, Suarez P, Lotsch A, et al. Growing-season rainfall and scenarios of future change in southeast Africa: implications for cultivating maize [J]. Climate Research, 2009, 40(2-3):147-161.

24.MASILIONYTE L, MAIKŠTÉNIENE S. The effect of agronomic and meteorological factors on the yield of main and catch crops [J]. Zemdirbyste-Agriculture, 2011, 98(3):235244.

25.Turner NC, Rao K. Simulation analysis of factors affecting sorghum yield at selected sites in eastern and southern Africa, with emphasis on increasing temperatures [J]. Agricultural Systems, 2013, 121(2013):53-62.

26.Hijmans RJ, Cameron SE, Parra JL, et al. Very high resolution interpolated climate surfaces for global land areas [J]. International journal of climatology, 2005, 25(15):1965-1978.

27.Solomon S. Climate change 2007-the physical science basis: Working group I contribution to the fourth assessment report of the IPCC [M]: Cambridge University Press, 2007, 11-18

28. Washington R, New M, Hawcroft M, et al. Climate change in CCAFS regions: Recent trends, current projections, crop-climate suitability, and prospects for improved climate model information [J]. Climate Change, Agriculture and Food Security, 2012:2-7.

29.Gaffin SR, Rosenzweig C, Xing X, et al. Downscaling and geo-spatial gridding of socioeconomic projections from the IPCC Special Report on Emissions Scenarios (SRES) [J]. Global Environmental Change, 2004, 14(2):105-123.

30.Gupta S, Larson W. Estimating soil water retention characteristics from particle size distribution, organic matter percent, and bulk density [J]. Water Resources Research, 1979, 15(6):1633-1635.

31.Jacobsen K. Comparison of ASTER GDEMs with SRTM height models. EARSeL Symposium, Dubrovnik Remote Sensing for Science, Education and Natural and Cultural Heritage; 2010, 521-526.

32.Malczewski J. GIS-based land-use suitability analysis: a critical overview [J]. Progress in planning, 2004, 62(1):3-65.

33.Alejandro CS, Jorge LB. Delineation of suitable areas for crops using a Multi-Criteria Evaluation approach and land use/cover mapping: a case study in Central Mexico [J]. Agricultural Systems, 2003, 77(2):117-136.

34.Wander MM, Yang X. Influence of tillage on the dynamics of loose-and occludedparticulate and humified organic matter fractions [J]. Soil Biology and Biochemistry, 2000, 32(8):1151-1160

35.Eastman J. Multi-criteria evaluation and GIS [J]. Geographical information systems, 1999, $1: 493-502$.

36.Drobne S, Lisec A. Multi-attribute Decision Analysis in GIS: Weighted Linear Combination and Ordered Weighted Averaging [J]. Informatica (03505596), 2009, 33(4):459-474.

37. You L, Wood S. An entropy approach to spatial disaggregation of agricultural production [J]. Agricultural Systems, 2006, 90(1):329-347.

38.Kalogirou S. Expert systems and GIS: an application of land suitability evaluation [J]. Computers, Environment and Urban Systems, 2002, 26(2-3):89-112.

39.Sultan B, Roudier P, Quirion P, et al. Assessing climate change impacts on sorghum and millet yields in the Sudanian and Sahelian savannas of West Africa [J]. Environmental Research Letters, 2013, 8(1):14-40.

40.Thornton PK, Jones PG, Alagarswamy G, et al. Spatial variation of crop yield response to climate change in East Africa [J]. Global Environmental Change, 2009, 19(1):54-65.

41.Pellet D, El-Sharkawy MA. Cassava varietal response to phosphorus fertilization. I. Yield, biomass and gas exchange [J]. Field Crops Research, 1993, 35(1):1-11.

42.Ziervogel G, Bharwani S, Downing TE. Adapting to climate variability: pumpkins, people and policy. Natural Resources Forum: Wiley Online Library; 2006, 294-305.

43.Jarvis A, Ramirez-Villegas J, Campo BVH, et al. Is cassava the answer to African climate change adaptation? [J]. Tropical Plant Biology, 2012, 5(1):9-29. 
